\title{
Effect of Salicylic Acid 3\% + Benzoic Acid 6\% (Whitfield's Ointment), Clotrimazole 1\% Cream, and Systemic Terbinafine on Mild-to-Moderate Tinea Corporis: A Randomized Comparative Study
}

\author{
Vishwas Rahangdale ${ }^{1} \quad$ Sneha Deshmukh ${ }^{1} \quad$ Vaishnavi $^{1} \quad$ Bhushan Madke $^{1} \quad$ Adarsh Lata Singh $^{1}$
} ${ }^{1}$ Department of Dermatology, Jawaharlal Nehru Medical College,
Datta Meghe Institute of Medical Sciences, Wardha, Maharashtra,
India

Int J Recent Surg Med Sci:2020;6:49-52

\begin{abstract}
Address for correspondence Adarsh Lata Singh, MD, MPhil, PhD, Department of Dermatology, Jawaharlal Nehru Medical College, Datta Meghe Institute of Medical Sciences Sawangi (Meghe), Wardha, Maharashtra 442004, India (e-mail: dradarshlata@yahoo.co.in).
\end{abstract}

\begin{abstract}
Keywords

- BSA

- Whitefield ointment

- clotrimazole

- terbinafine

- tinea corporis

Introduction The various epidemiological studies conducted on dermatophytic infection in different parts of India have concluded that there is a rising prevalence of dermatophytosis, with change in clinical presentation of infection. Although most of the therapeutic interventions show sufficient effect, there is a need for objective high-quality randomized comparative study to evaluate the effects of intervention, which can provide reliable evidence for clinical practice. Therefore, keeping this need in mind, we undertook this research work. To date, to the best of our knowledge, the inclusion of body surface area (BSA) as a tool for the evaluation of clinical improvement in dermatophytosis infection has not been considered.

Objective The aim of this study was to assess the effect of topical antifungal as a monotherapy in naive and in combination with systemic antifungal drug in relapse cases of mild-to-moderate tinea corporis, to study and compare the efficacy of Clotrimazole $1 \%$ and Whitfield's ointment as a monotherapy in mild-to-moderate cases of tinea corporis, and to study and compare the efficacy of combination of systemic terbinafine with Whitfield's ointment and with clotrimazole $1 \%$ in mild-to-moderate relapsed cases of tinea corporis.

Materials and Methods A total of 102 patients with mild-to-moderate tinea corporis who fulfilled the inclusion and exclusion criteria were enrolled. The naive patients for monotherapy and relapsed cases for a combination of systemic and topical antifungal drugs were randomly distributed.

Results Predominance of males than females and the duration of disease for more than 6 weeks were observed. There was a significant reduction of infection in all the groups after 4 weeks, but early response was observed with clotrimazole as a monotherapy and in combination of clotrimazole with systemic drug.

Conclusion Topical drugs as a monotherapy in naive and in combination of topical and systemic antifungal drug in relapsed cases were effective, but to achieve zero BSA, treatment for more than 4 weeks is required.
\end{abstract}

published online

July 8,2020
DOI https://doi.org/

$10.1055 / \mathrm{s}-0040-1714163$ ISSN 2455-7420.

\footnotetext{
(C) 2020. Medical and Surgical Update Society.

This is an open access article published by Thieme under the terms of the Creative Commons Attribution-NonDerivative-NonCommercial-License, permitting copying and reproduction so long as the original work is given appropriate credit. Contents may not be used for commercial purposes, or adapted, remixed, transformed or built upon. (https://creativecommons.org/licenses/by-nc-nd/4.0/)

Thieme Medical and Scientific Publishers Pvt. Ltd., A-12, 2nd Floor, Sector 2, Noida-201301 UP, India
} 


\section{Introduction}

The current prevalence of dermatophytosis infections in India ranges from 36.6 to $78.4 \% .^{1}$ Dermatophyte, infections such as tinea corporis and other tinea infections having recurrences, severe pruritus, do not respond to treatment lead to a significantly negative impact on life of patient with regard to occupational and psychosocial aspects..$^{2-7}$

Because of the aforementioned scenario, management of dermatophyte infections is becoming challenging for all dermatologists across the globe and also for our country India where it is just like an epidemic. From the past two years, the dermatologists are feeling helpless as options to treat dermatophyte infections are less and lesions are not responding to conventional line of management. ${ }^{1}$

There are various epidemiological reasons for the aforementioned presentation of clinical scenario as chronic or recurrent dermatophytosis which are creating treatment challenges in a similar way as dermatologists face in known difficulty to treat dermatoses such as psoriasis, vitiligo, alopecia, and pemphigus. ${ }^{8}$ There is no consensus or guidelines for the management of these cases due to which dermatologists are using a combination of different groups of topical and oral antifungals, increasing doses of antifungals, increasing duration of treatment, and also using retinoids for the treatment of these recalcitrant dermatophyte cases; the major concern is that it is more of a hit and trial rather than evidence-based approach. It is felt that well-designed studies comparing different antifungals or modalities are required. ${ }^{8}$ The aforementioned modifications in treatment are most commonly based on experience and primarily based on observational cohort studies. ${ }^{8}$

Although most of the interventions show sufficient therapeutic effect, there is a need for more high-quality randomized comparative studies to evaluate the effects of these interventions, which can ultimately provide reliable evidence for clinical practice. ${ }^{9}$

Well-designed randomized controlled trials (RCTs) by experts in the field are required to address the need of an evidence-based practical approach. ${ }^{10,11}$ In addition, to increase the objectivity also requires an application of BSA (body surface area) to assess clinical improvement in the effectivity of antifungal drugs. ${ }^{1}$ There is also paucity of evidences on comparative studies on the combination of systemic and topical drug therapy versus monotherapy. ${ }^{3}$ Therefore, keeping that gaps in mind, we have undertaken this research work. To date, to the best of our knowledge, the inclusion of BSA as a tool for the evaluation of clinical improvement in dermatophytosis has not been considered.

The aim of this study was to assess the overall effect of topical antifungal as a monotherapy and in combination with systemic antifungal drugs in mild-to-moderate cases of tinea corporis. The following objectives were formulated for the study as: (1) to study the efficacy of clotrimazole $1 \%$ and Whitfield's ointment (salicylic acid $3 \%$ with benzoic acid $6 \%$ as a monotherapy in mild-to-moderate naive cases of Tinea corporis, (2) to study the efficacy of the combination of systemic terbinafine with Whitfield's ointment (salicylic acid 3\% with benzoic acid 6\%) and with clotrimazole $1 \%$ in mild-to-moderate relapsed cases of tinea corporis, and (3) to compare the efficacy of these topical drugs as a monotherapy and in combination of systemic drug with topical antifungal drugs in naive and relapsed cases of tinea corporis, respectively.

\section{Materials and Methods}

A randomized comparative study was performed in the Department of Dermatology, Venereology, \& Leprosy, Jawaharlal Nehru Medical College, Acharya Vinoba Bhave Rural Hospital (AVBR) Hospital. The randomization was performed using sequential numbering. A total of 102 patients diagnosed with tinea corporis fulfilled the inclusion and exclusion criteria and gave consent to participate in the study. The inclusion criteria were as follows: age $>18$ years, both genders, neither history of any treatment in the past for naive group and at least no treatment both topical and systemic for last 8 weeks for relapse group and 3\% to 10\% BSA only. Patients suffering from liver and renal disease, depression, immunosuppression, lupus, and so on, pregnant or lactating female, those allergic to salicylic acid, benzoic acid, and clotrimazole drugs, and those on any medication such as Ayurvedic or homeopathy were excluded. The detailed history was taken, and using clinical examination and confirmation by $10 \% \mathrm{KOH}$ (potassium hydroxide), the diagnosis was made. The naive ${ }^{9}$ cases (no treatment in the past) were randomized to group A (clotrimazole 1\%) and group B(salicylic acid $3 \%+$ benzoic acid $6 \%$ cream twice daily application) for 4 weeks. The criteria of relapse ${ }^{9}$ denote that the occurrence of dermatophytosis infection after a longer period of infection-free interval ( $6-8$ weeks) in a patient who has been cured clinically by intervention. ${ }^{1}$ The relapsed cases were randomized to group C (clotrimazole $1 \%+$ tablet terbinafine $250 \mathrm{mg}$ once daily) and group D (salicylic acid 3\% + benzoic acid $6 \%$ + tablet terbinafine $250 \mathrm{mg}$ once daily) for 4 weeks. All patients with tinea corporis in all groups received one tablet of levocetirizine $10 \mathrm{mg}$ daily for pruritus. The follow-up visit was after 2 weeks up to 4 weeks. BSA ${ }^{9}$ was calculated as the area of palm from the wrist to the tip of the fingers and was considered roughly $1 \%$ of the BSA. Less than $3 \%$ BSA was counted as mild infection, 3 to $10 \%$ BSA as moderate infection, and more than $10 \%$ BSA as severe infection. ${ }^{5}$

Statistical analysis was performed using descriptive and inferential statistics using chi-square test and Student's unpaired t-test. SPSS 24.0 Version (IBM Corp., Armonk, New York, United States) and GraphPad Prism Version 7.0 were used for analysis, and $p<0.05$ was considered as a level of significance.

\section{Results}

A randomized comparative study to assess the effectivity of salicylic acid 3\% + benzoic acid 6\% (Whitfield's ointment), clotrimazole $1 \%$ cream and systemic terbinafine in mild-to-moderate tinea corporis was conducted from May 19 to October 19 at the Department of Dermatology, 
Venereology, \& Leprosy, AVBR Hospital. A total of 102 patients with mild-to-moderate tinea corporis were enrolled after obtaining written consent. After analysis, the results were depicted in the tables. The mean age observed was 30 to 40 years, predominantly males were affected, and the duration of disease was more than 6 weeks (-Tables 1-4). Early and more response was seen with clotrimazole than with a combination of salicylic acid and benzoic acid either as a monotherapy or in combination with systemic drugs.

\section{Discussion}

A systematic analysis published in the British Journal of Dermatology and Cochrane review pointed out the need for well-organized RCTs on the treatment of dermatophyte infections so that evidences can be generated to aid clinical dermatology practice. ${ }^{9}$

Table 1 Mean age of patients in groups $A$ and $B$

\begin{tabular}{|l|l|l|l|}
\hline & Group A & Group B & $\chi^{2}$ value \\
\hline $\begin{array}{l}\text { Total number } \\
\text { of patients }\end{array}$ & 28 & 25 & $\begin{array}{l}1.73, p=0.78, \\
\text { NS }\end{array}$ \\
\hline $\begin{array}{l}\text { Mean } \pm \text { SD of } \\
\text { age, years }\end{array}$ & $37.92 \pm 18.09$ & $33.60 \pm 13.57$ & \\
\hline
\end{tabular}

Abbreviations: NS, nonsignificant; SD, standard deviation.

Table 2 Mean age of patients in groups C and D

\begin{tabular}{|l|l|l|l|}
\hline & Group C & Group D & $\chi^{2}$ value \\
\hline $\begin{array}{l}\text { Total } \\
\text { number of } \\
\text { patients }\end{array}$ & 25 & 24 & $\begin{array}{l}4.51, p=0.34, \\
\text { NS }\end{array}$ \\
\hline $\begin{array}{l}\text { Mean } \pm \text { SD } \\
\text { of age, years }\end{array}$ & $36.08 \pm 16.74$ & $37.50 \pm 14.87$ & \\
\hline
\end{tabular}

Abbreviations: NS, nonsignificant; SD, standard deviation.

Note: According to Table 1 and 2, distribution of patients on the basis of age between groups $A$ and $B$ and groups $C$ and $D$ was having a nonsignificant difference, respectively.

Table 3 Gender wise distribution of patients in groups A and B

\begin{tabular}{|l|l|l|l|}
\hline Gender & Group A & Group B & $\chi^{2}$ value \\
\hline Male & $18(64.29 \%)$ & $15(60 \%)$ & \multirow{2}{*}{$0.10, p=0.74$, NS } \\
\cline { 1 - 3 } Female & $10(35.71 \%)$ & $10(40 \%)$ & \\
\cline { 1 - 3 } Total & $28(100 \%)$ & $25(100 \%)$ & \\
\cline { 1 - 2 } & &
\end{tabular}

Abbreviation: NS, nonsignificant.

Note: Predominantly males were infected than the females and the difference was nonsignificant.

Table 4 Gender wise distribution of patients in groups $C$ and D

\begin{tabular}{|l|l|l|l|}
\hline Gender & Group C & Group D & \multirow{2}{*}{$\chi^{2}$ value } \\
\hline Male & $13(52 \%)$ & $13(54.17 \%)$ & \multirow{2}{*}{$0.02 p=0.87$, NS } \\
\cline { 1 - 3 } Female & $12(48 \%)$ & $11(45.83 \%)$ & \\
\cline { 1 - 2 } Total & $25(100 \%)$ & $24(100 \%)$ & \\
\cline { 1 - 2 } & &
\end{tabular}

Abbreviation: NS, nonsignificant.

Note: Predominantly males were infected than the females and the difference was nonsignificant.
On analysis of mean of age of cases in all four groups, it was observed that the minimum was $33.60 \pm 13.57$ years and the maximum was $37.92 \pm 18.09$ years; this explains that almost all age groups of patients got infections. The cause of this may be the adoption of western culture, in which mostly all wear tight clothes. ${ }^{11}$ In our country, most of the time, there is hot and humid climate in a year; according to which one should wear loose and cotton clothes. Another reason can be lifestyle for getting infections frequently. ${ }^{11}$

Males dominantly got infected, as they mostly work outdoor, which is most of the time hot and humid climate, ${ }^{12}$ and the other reason can be that men come to the hospital early but female either hesitate to go to the hospital or may be unaware as mostly our hospital caters to rural population. ${ }^{12}$

The duration of tinea infection is an important parameter as the duration of infection increases the possibility of use of home remedies, irrational treatment, or incomplete treatment increases, which affect the treatment outcome. ${ }^{11}$ As shown in - Table 5, the mean duration of disease was $6.98 \pm 6.02$ weeks in group $A$ and $6.56 \pm 6.18$ weeks in group B, which explains that the maximum number of patients have infection for more than 6 weeks. This implies that after getting infection, patients were not reported early, which can be either because they were not aware of dermatophyte infections or delayed till the pruritus became severe or intolerable. Another important factor that can be responsible for late reporting is casual approach of the patients toward cutaneous diseases.

In groups $C$ and $D(-$ Table 6 ), the mean duration was $10.42 \pm 14.96$ and $16.77 \pm 20.64$ weeks, respectively, because in these groups patients had a history of relapse.

On the basis of analysis of BSA before and after treatment with topical drug as monotherapy, it can be said that both clotrimazole and Whitfield's ointment were effective (-Table 7). But in group A treated with topical clotrimazole $1 \%$, a more significant reduction of BSA after 2 weeks was observed in comparison to Whitfield's ointment. This indicates that clotrimazole $1 \%$ gives early relief, whereas after 4 weeks both are equally effective. It should be noted that both topicals were effective, but there was a need to increase the duration of application, as BSA did not reduce to zero after 4 weeks.

In the relapse group after treatment with combination of systemic and topical antifungal drug, it can be said

Table 5 Distribution of patients in group A and B according to duration

\begin{tabular}{|c|c|c|c|}
\hline $\begin{array}{l}\text { Duration } \\
\text { (weeks) }\end{array}$ & Group A & Group B & $\chi^{2}$ value \\
\hline Upto 2 & $9(32.14 \%)$ & $7(28 \%)$ & \multirow{6}{*}{$\begin{array}{l}3.56, p=0.31 \\
\text { NS }\end{array}$} \\
\hline $3-4$ & $6(21.43 \%)$ & $8(32 \%)$ & \\
\hline $5-6$ & $0(0 \%)$ & $2(8 \%)$ & \\
\hline$>6$ & $13(46.43 \%)$ & $8(32 \%)$ & \\
\hline Total & $28(100 \%)$ & $25(100 \%)$ & \\
\hline Mean \pm SD & $6.98 \pm 6.02$ & $6.56 \pm 6.18$ & \\
\hline
\end{tabular}

Abbreviations: NS, nonsignificant; SD, standard deviation. Note: The maximum number of cases was having more than 6 weeks of duration, and the difference between groups was nonsignificant. 
Table 6 Distribution of patients in groups C and D according to duration

\begin{tabular}{|c|c|c|c|}
\hline $\begin{array}{l}\text { Duration } \\
\text { (weeks) }\end{array}$ & Group C & Group D & $\chi^{2}$ value \\
\hline Upto 2 & $6(24 \%)$ & $6(25 \%)$ & \multirow{6}{*}{$\begin{array}{l}2.01, p=0.56 \\
\text { NS }\end{array}$} \\
\hline $3-4$ & $6(24 \%)$ & $3(12.50 \%)$ & \\
\hline $5-6$ & $0(0 \%)$ & 1 (4.17\%) & \\
\hline$>6$ & 13 (52\%) & $14(58.33 \%)$ & \\
\hline Total & 25 (100\%) & $24(100 \%)$ & \\
\hline Mean \pm SD & $10.42 \pm 14.96$ & $16.77 \pm 20.64$ & \\
\hline
\end{tabular}

Abbreviations: NS, nonsignificant; SD, standard deviation.

Note: The maximum number of cases were having more than 6 weeks of duration, and the difference between groups was nonsignificant.

Table 7 Comparison of BSA in groups A and B at 0, 2, and 4 weeks

\begin{tabular}{|l|l|l|l|l|}
\hline \multirow{2}{*}{$\begin{array}{l}\text { Duration } \\
\text { (weeks) }\end{array}$} & \multicolumn{2}{|c|}{$\begin{array}{c}\text { Comparison of BSA } \\
\text { (Mean } \pm \text { SD) }\end{array}$} & \multirow{2}{*}{-Value } & $p$-Value \\
\cline { 2 - 4 } & Group A & Group B & & \\
\hline 0 & $1.17 \pm 0.69$ & $1.50 \pm 0.87$ & 1.54 & 0.12 , NS \\
\hline 2 & $0.20 \pm 0.34$ & $0.46 \pm 0.54$ & 2.04 & $0.047, \mathrm{~S}$ \\
\hline 4 & $0 \pm 0$ & $0.10 \pm 0.20$ & 1.66 & $0.10, \mathrm{NS}$ \\
\hline
\end{tabular}

Abbreviations: NS, nonsignificant; S, significant; SD, standard deviation. Note: significant reduction in infection was observed in both groups after 4 weeks, but early response was observed in group A than group B. Student's unpaired $t$-test was used for assessing values.

that both combinations were effective. But the combination of systemic terbinafine and topical clotrimazole drug showed a more significant reduction of BSA after 4 weeks in comparison with the combination of systemic terbinafine and topical Whitfield's ointment. None showed early significant reduction of BSA and gave zero BSA at 4 weeks

\section{(-Table 8).}

We also noted that there was a need to increase the duration of treatment to make BSA zero in all the groups. The reason of choosing these drugs as they were of different antifungal groups, paucity of RCT with these and they are cost effective then the newer drugs. During analysis felt limitations of data on follow up visits not done till BSA becomes zero. In future, similar types of studies with other drugs and follow-up visits, till BSA becomes zero, need to be conducted.

\section{Conclusion}

We can conclude that topical clotrimazole and Whitefield's ointment are effective in naive patients, but clotrimazole gives early relief. A combination of systemic terbinafine with clotrimazole and Whitfield's ointment was also effective in relapse cases, but more reduction in BSA observed with a combination of terbinafine and clotrimazole. There is a need to make people aware of the cause of spread of dermatophyte infection.

\section{Funding}

None.
Table 8 Comparison of BSA in groups C and D at 0, 2, and 4 weeks

\begin{tabular}{|l|l|l|l|l|}
\hline \multirow{2}{*}{$\begin{array}{l}\text { Duration } \\
\text { (weeks) }\end{array}$} & \multicolumn{2}{|c|}{$\begin{array}{c}\text { Comparison of BSA } \\
\text { (Mean } \pm \text { SD) }\end{array}$} & \multirow{2}{*}{-Value } & $p$-Value \\
\cline { 2 - 4 } & Group C & Group D & & \\
\hline 0 & $3.72 \pm 1.13$ & $3.31 \pm 0.88$ & 1.39 & 0.16, NS \\
\hline 2 & $1.36 \pm 0.82$ & $1.33 \pm 0.56$ & 0.17 & 0.86, NS \\
\hline 4 & $0.15 \pm 0.32$ & $0.40 \pm 0.37$ & 2.31 & $0.026, S$ \\
\hline
\end{tabular}

Abbreviations: NS, nonsignificant; S, significant; SD, standard deviation. Note: Significant reduction in infection was observed in both groups after 4 weeks, but early response was observed in group C than group D. Student's unpaired $t$-test was used for assessing values.

\section{Conflict of Interest}

None declared.

\section{Acknowledgments}

We thank all the support given by the patients, statistician, and administrative authority of the institution.

\section{References}

1 Rajagopalan M, Inamadar A, Mittal A, et al. Expert Consensus on The Management of Dermatophytosis in India (ECTODERM India). BMC Dermatol 2018;18(1):6

2 Jerajani H, Janaki C, Kumar S, Phiske M. Comparative assessment of the efficacy and safety of sertaconazole (2\%) cream versus terbinafine cream (1\%) versus luliconazole $(1 \%)$ cream in patients with dermatophytoses: a pilot study. Indian J Dermatol 2013;58(1):34-38

3 Sahoo AK, Mahajan R. Management of tinea corporis, tinea cruris, and tinea pedis: a comprehensive review. Indian Dermatol Online J 2016;7(2):77-86

4 Lakshmanan A, Ganeshkumar P, Mohan SR, Hemamalini M, Madhavan R. Epidemiological and clinical pattern of dermatomycoses in rural India. Indian $\mathrm{J}$ Med Microbiol 2015;33(Suppl):134-136

5 Sharma Y, Jain S, Chandra K, Khurana VK, Kudesia M. Clinicomycological evaluation of dermatophytes and non-dermatophytes isolated from various clinical samples: a study from north India. J Res Med Sci 2012;17(8):817-818

6 Agarwal US, Saran J, Agarwal P. Clinico-mycological study of dermatophytes in a tertiary care centre in Northwest India. Indian J Dermatol Venereol Leprol 2014;80(2):194

7 Sahai S, Mishra D. Change in spectrum of dermatophytes isolated from superficial mycoses cases: first report from Central India. Indian J Dermatol Venereol Leprol 2011;77(3):335-336

8 Dogra S, Uprety S. The menace of chronic and recurrent dermatophytosis in India: is the problem deeper than we perceive. ? Indian Dermatol Online J 2016;7(2):73-76

9 van Zuuren EJ, Fedorowicz Z, El-Gohary M. Evidence-based topical treatments for tinea cruris and tinea corporis: a summary of a Cochrane systematic review. $\mathrm{Br} \mathrm{J}$ Dermatol 2015;172(3):616-641

10 Thaker SJ, Mehta DS, Shah HA, Dave JN, Kikani KM. A comparative study to evaluate efficacy, safety and cost-effectiveness between Whitfield's ointment + oral fluconazole versus topical $1 \%$ butenafine in tinea infections of skin. Indian J Pharmacol 2013;45(6):622-624

11 Verma S, Madhu R. The great Indian epidemic of superficial dermatophytosis: An appraisal. Indian J Dermatol 2017;62(3):227-236

12 Majid I, Sheikh G, Kanth F, Hakak R. Relapse after oral terbinafine therapy in dermatophytosis: a clinical and mycological study. Indian J Dermatol 2016;61(5):529-533 